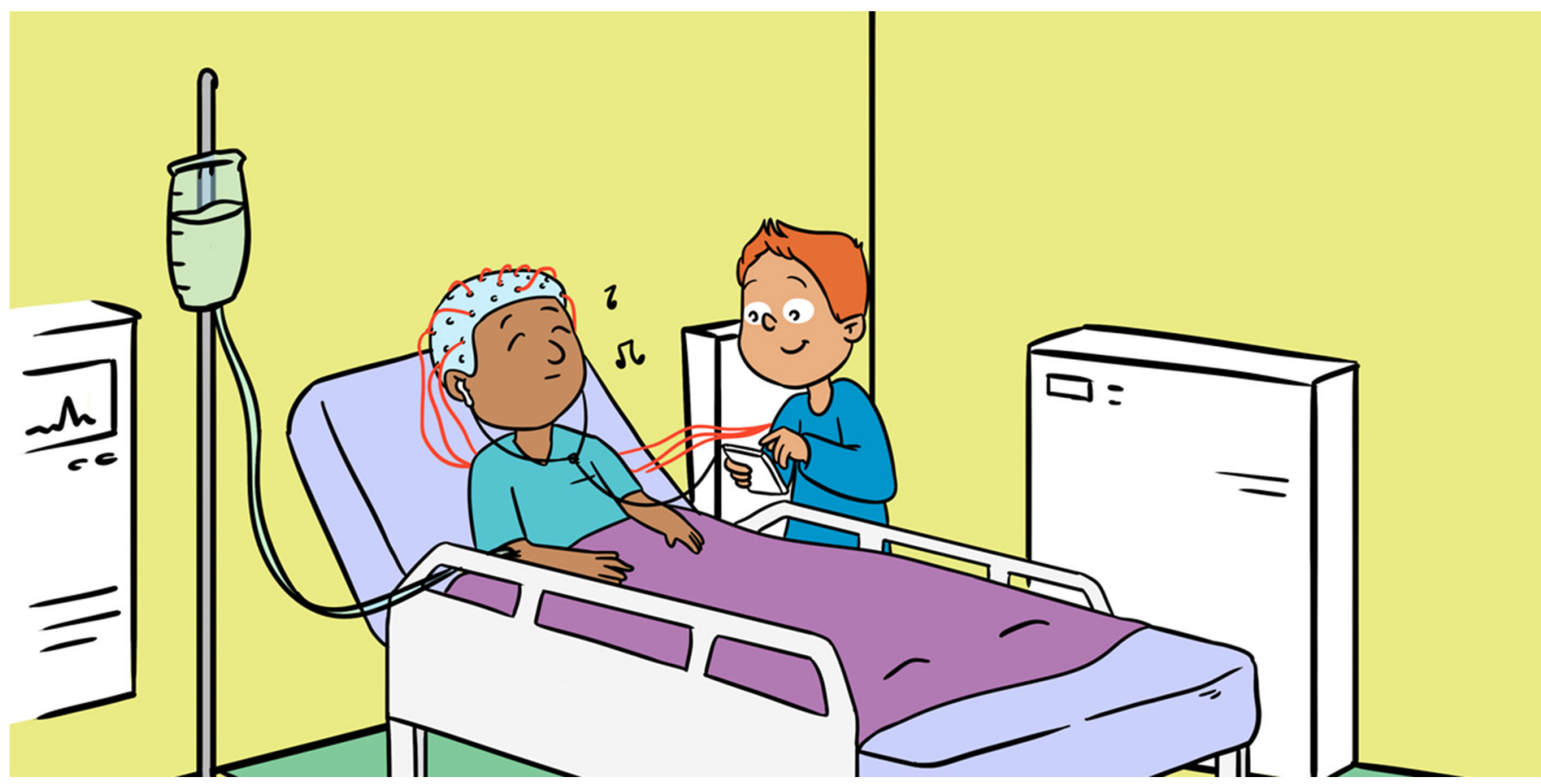

\title{
CAN THE BRAIN OF A PATIENT IN A COMA REACT TO SOUNDS?
}

\section{Athina Tzovara ${ }^{*}$ and Marzia De Lucia ${ }^{2}$}

${ }^{1}$ Helen Wills Neuroscience Institute, University of California, Berkeley, Berkeley, CA, United States

2 Laboratoire de Recherche en Neuroimagerie, Department of Clinical Neurosciences, Lausanne University Hospital and University of Lausanne, Lausanne, Switzerland

\section{YOUNG REVIEWERS:}

\begin{tabular}{|l|l}
\hline & FLORIMONT \\
AGES: $15-16$
\end{tabular}

When people are in comas, they are unconscious and cannot communicate with their environment. They cannot speak and their eyes are closed. They look as if they are asleep. However, the brain of a coma patient may continue to work. It might "hear" the sounds in the environment, like the footsteps of someone approaching or the voice of a person speaking. In this article, we will see how we can measure brain activity in patients who are comatose and how the brains of coma patients react to sounds. These reactions can inform medical doctors of whether the patients will awake from the coma.

\section{WHAT HAPPENS WHEN SOMEONE IS IN A COMA?}

Imagine a person who has fallen into a coma. A coma can occur from many causes, such as a traumatic brain injury, a stroke, or maybe loss of oxygen from a near drowning. The comatose person is lying still on the bed, with eyes closed. The person does not show any sign of 
ELECTROENCEPHALOGRAPHY (EEG)

A tool that helps clinicians and researcher to measure the electric activity produced by the brain, by placing electrodes on a person's head. communication with the environment. We speak to the comatose person, but he or she does not respond and seems indifferent to everything that is happening. When a person is in a coma, this person is in what we call an unconscious state. But is the brain of a coma patient still working?

There is a good chance that the brain of a person in a coma continues to process events from the environment, for example the footsteps of someone approaching or the sound of your voice when you speak to them [1]. To measure the brain activity of a person in a coma, we use a tool called electroencephalography (EEG). EEG helps us record the activity of cells in the brain called neurons. We can measure the electrical activity of brain cells by placing electrodes on a person's head. These electrodes are inside a cap. Imagine something like a swimming cap with a lot of holes in it. Electrodes are inserted into these holes and touch the skin of the scalp. Every time that we see or hear something, neurons in the brain fire. This firing can change the electrical activity that we measure on the head with EEG. EEG is used to study the neural functions of coma patients, because it is easy to use at the patients' bed without causing any pain or discomfort.

Importantly, EEG can be used to help medical doctors diagnose how serious a person's coma is, according to their brain functions. Usually, coma patients have their eyes closed and cannot see what happens around them. But their ears keep receiving sounds from the environment. In some cases, the brains of coma patients can process sounds, for example the voice of someone speaking to them [2]. Coma patients may not understand those sounds, and not remember them when they awake. Still, their brains may receive and process the sounds to some degree. With EEG, we have the unique opportunity to study whether the brain of a coma patient responds to sounds, even when this patient cannot communicate with us. What is really amazing is that by studying brain responses to sounds, medical doctors can evaluate whether a patient is likely to awake from the coma and sometimes even determine what the patient's neurological condition will be after awakening [3].

\section{STUDYING BRAIN RESPONSES TO SOUNDS, TO PREDICT WHICH PATIENTS WILL AWAKE FROM A COMA}

Let us discuss one cause of coma, decreased oxygen delivery to the brain. Our brain cells, like all cells, need oxygen to function. Brain cells receive this oxygen from blood circulating in the brain. If the heart stops working, no oxygen will reach the brain. It is then common to lose consciousness and fall into a coma. A treatment for coma patients is to lower the body temperature in order to protect their brains from excessive trauma. Patients remain in this decreased body temperature 
STANDARD SOUNDS

Sounds that are

frequently repeated.

\section{DEVIANT SOUNDS}

Different sounds from the standard ones, they cause a surprise reaction in the brain.

\section{Figure 1}

(A) We presented a series of sounds to coma patients. Most of the time, the sounds were identical to one another (standard). Sometimes, the standard sound was replaced by a different sound (deviant). We measured the brain responses of coma patients to every sound that they heard, by a tool called electroencephalography. This allows us to study how the brain of patients is reacting to sounds and whether it can tease apart standard (gray) from deviant (yellow) ones. (B) We grouped brain responses to different types of sounds together by using mathematical models. The gray and yellow circles show the groups of responses to standard and deviant sounds. We then used these groups to examine whether the brain of a patient can discriminate standard from deviant sounds.

for $24 \mathrm{~h}$ and then their bodies are rewarmed. Hopefully, patients can later awake from their comas and regain consciousness.

It is important for medical doctors to have ways of knowing which coma patients are likely to awake. This information will help them to provide the best treatment for the patients, and also to inform the patients' families about the likelihood of recovery. In most hospitals, there are clinical tests to find out which coma patients are not doing well. But there are very few tests to predict when a patient will awake, and an accurate prediction is usually challenging. In our study, we aimed at developing a test that predicts whether a patient will awake from a coma. For this test, we studied the brain responses of coma patients to sounds [4]. We inserted earphones into the patients' ears and played sounds to them (Figure 1).

The sounds we played were very short artificial "bips" and we presented them in a quick and rhythmic way. Imagine, for example, a series of sounds coming from tapping your fingers repeatedly, or from playing a musical note on the piano. Imagine listening to the same note being played over and over again. If this note is replaced all of a sudden with a different note, your brain will show a "surprise" response to the different note, because it is unexpected. In our study, we call the sounds that are repeated "standard sounds" and the different sounds "deviant sounds." You can see an example of the sounds in Figure 1, shown in gray (standard sounds) and yellow (deviant sounds). You can also hear some of these sounds in Audio File 1. We presented these sounds to the patients and while we measured their brain activity with EEG. Our goal was to study how their brains reacted to the series of sounds.

The brain activity that we measure using EEG can be "drawn," using different colors to create maps (Figure 2). Different colors on the maps show that different brain regions were activated in response to sounds. Brain functions can be different from one patient to another. For this reason, we computed a mathematical model to find patterns in brain responses to standard or deviant sounds (Figure 1B). We used these patterns to measure whether the patients' brains could discriminate the different types of sounds (Figure 1B). We repeated this analysis two

\section{A. Sounds presented to the patients}

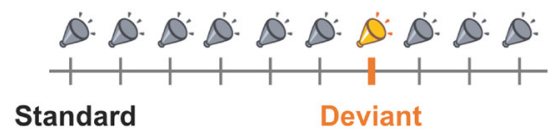

B. Grouping brain responses to the sounds

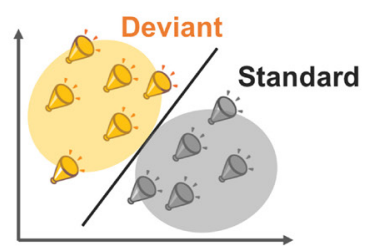


Figure 2

We recorded brain responses from a patient on the first and second day of coma.

For each day of coma you can see the maps of EEG responses to standard and deviant sounds. Each map shows the measurement performed across the electrodes located on the head of the patient in order to uniformly cover the scalp surface. Different colors correspond to different values of the electric activity produced by the brain and measured by the EEG. You can see that, on the first day of coma, the brain responses to standard and deviant sounds were almost identical to each other, as they have similar colors (blue to the top, red to the bottom). One the second day, you can see that the responses to standard and deviant sounds are very different from each other, and the maps do not look similar any more. This means that the ability of the patient's brain to tease the sounds apart improved from the first to the second day of coma. In our experiments, we found that this improvement means that the patient is likely to awake from the coma. Indeed, some days after our recordings this patient awoke. times, in the first and second day of coma. The first time we measured, the body temperature of the patients was lowered. The second time, the temperature was back to normal [5]. We then computed how the ability of the patients' brains to tell apart different types of sounds changed from the first to the second day.

\section{EEG AS A WINDOW INTO THE BRAIN OF COMA PATIENTS}

All the patients we included in this study were fully unconscious. Their bodies could not react to most of the things happening around them. What about their brains? Very interestingly, the brains of several patients reacted to the sounds that we played to them. Most patients' brains exhibited maps with different colors, depending on whether the sound played was standard or deviant. This suggests that the patients' brains could tell apart the sounds they heard. This ability to tell different sounds apart was almost as accurate as for healthy and awake people, at least for the first day of coma. In the second day, the ability to discriminate sounds was decreased for those patients who later died. This means that their brains could not easily tell whether a sound was standard or deviant. Our next question was whether this decreased ability to tell sounds apart was related to the patient's outcome.

For each patient, we measured how much the ability of the brain to tell sounds apart changed, from the first to the second day of coma. Only patients who later awoke from their comas showed an improvement in their brains' ability to discriminate sounds over the 2 days. In Figure 2, you can see the EEG responses to standard and deviant sounds for a patient who later awoke. On the second day of coma, the patient's

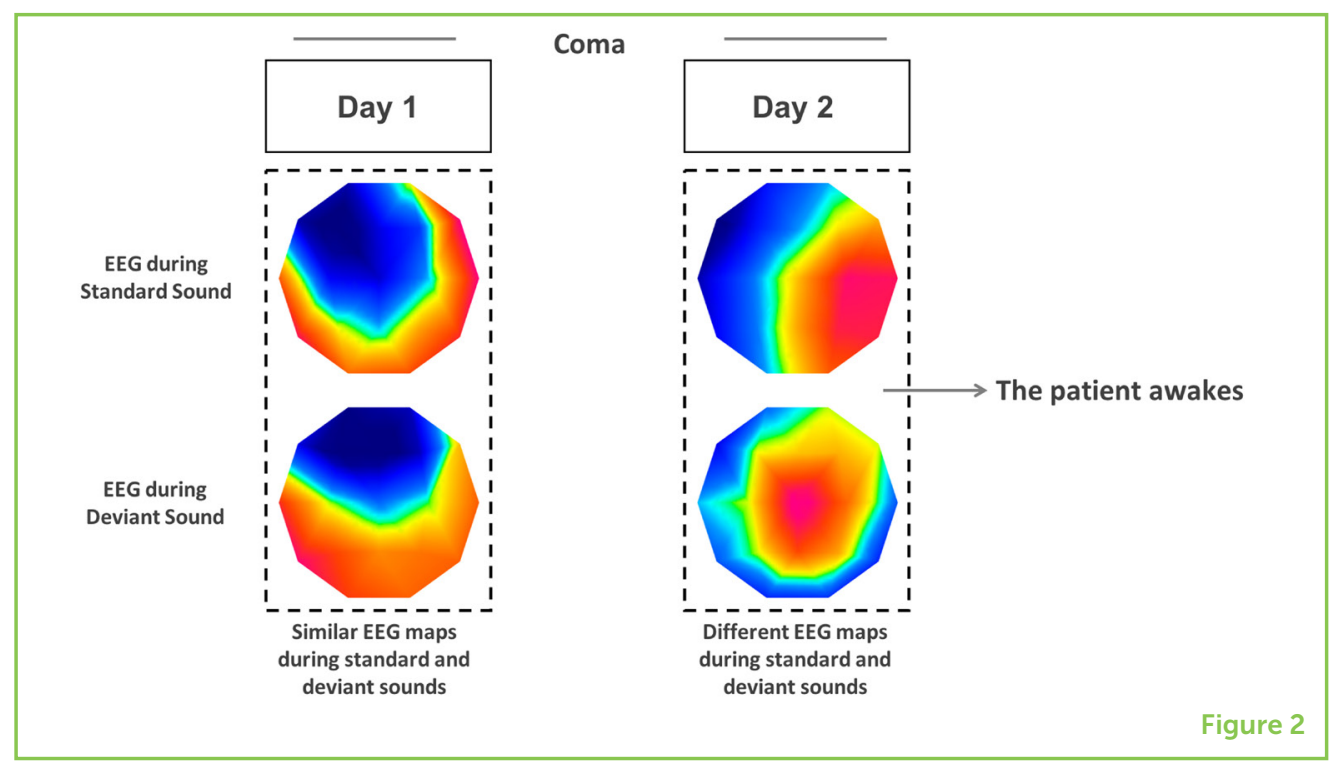


brain was able to better discriminate the two types of sounds than on the first day. A few days later, this patient awoke from the coma. The patient could communicate with friends and family again.

\section{CONCLUSIONS AND FUTURE WORK}

EEG is an exciting tool that gives a window into a person's brain functions, even when a person cannot communicate with us. Using this fascinating technique, we found that the brains of coma patients can react to sounds. Patients themselves were deeply unconscious and could not perceive what was happening around them. In our study, we used very simple and artificial sounds. In the future, we could repeat the experiment using speech or music. We could then examine whether the brain's ability to react to speech predicted the chances of a patient regaining consciousness.

\section{REFERENCES}

1. Laureys, S., Owen, A. M., and Schiff, N. D. 2004. Brain function in coma, vegetative state, and related disorders. Lancet 3:537-46. doi: 10.1016/S14744422(04)00852-X

2. Cossy, N., Tzovara, A., Simonin, A., Rossetti, A. O., and De Lucia, M. 2014. Robust discrimination between EEG responses to categories of environmental sounds in early coma. Front. Psychol. 5:155. doi: 10.3389/fpsyg.2014.00155

3. Juan, E., De Lucia, M., Tzovara, A., Beaud, V., Oddo, M., Clarke, S., et al. 2016. Prediction of cognitive outcome based on the progression of auditory discrimination during coma. Resuscitation 106:89-95. doi: 10.1016/j. resuscitation.2016.06.032

4. Tzovara, A., Rossetti, A. O., Juan, E., Suys, T., Viceic, D., Rusca, M., et al. 2016. Prediction of awakening from hypothermic postanoxic coma based on auditory discrimination. Ann. Neurol. 79:748-57. doi: 10.1002/ana.24622

5. Tzovara, A., Rossetti, A. O., Spierer, L., Grivel, J., Murray, M. M., Oddo, M., et al. 2013. Progression of auditory discrimination based on neural decoding predicts awakening from coma. Brain 136:81-9. doi: 10.1093/brain/aws264

SUBMITTED: 02 January 2019; ACCEPTED: 28 January 2019;

PUBLISHED ONLINE: 15 February 2019.

EDITED BY: Robert T. Knight, University of California, Berkeley, United States

CITATION: Tzovara A and De Lucia M (2019) Can the Brain of a Patient in a Coma React to Sounds? Front. Young Minds 7:19. doi: 10.3389/frym.2019.00019 
CONFLICT OF INTEREST STATEMENT: AT and MD are listed as inventors in a US patent entitled: "Method for predicting awakening in a comatose patient and computer-implemented method thereof" (application number: 14/383165). The patent is owned by Lausanne University Hospital and is currently not licensed.

COPYRIGHT @ 2019 Tzovara and De Lucia. This is an open-access article distributed under the terms of the Creative Commons Attribution License (CC BY). The use, distribution or reproduction in other forums is permitted, provided the original author(s) and the copyright owner(s) are credited and that the original publication in this journal is cited, in accordance with accepted academic practice. No use, distribution or reproduction is permitted which does not comply with these terms.

\section{YOUNG REVIEWERS}

\section{FLORIMONT, AGES: 15-16}

In our group of reviewers, we had a great atmosphere. Everyone worked well together. We laughed a lot during the review on the article on comas.

\section{AUTHORS}

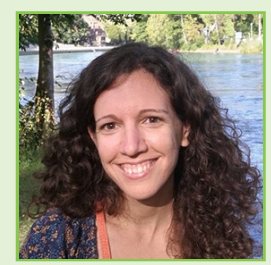

\section{ATHINA TZOVARA}

I am a Neuroscientist using computational techniques to study functions of the human brain. I am interested in consciousness and how the brain processes stimuli from the environment according to our levels of attention or awareness. I am currently working at the University of California, Berkeley, in the USA. *athina.tz@gmail.com

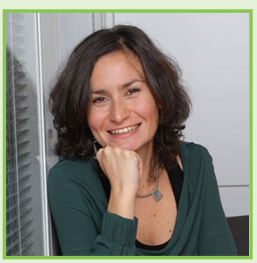

\section{MARZIA DE LUCIA}

I am a Researcher interested in brain functions that remain preserved when consciousness fades away, such as during coma or disorders of consciousness. I work at the University Hospital in Lausanne and I collaborate closely with other hospitals in Switzerland, in order to gather datasets from different clinical settings. 